\title{
GUARDIA SUIZA
}

Venustiano Reyes*

\section{Sofía comía mientras escuchaba a} Pedro. En realidad se veían poco, si dejamos a un lado el contexto estrictamente teológico, y no por falta de tiempo o alguna otra razón trivial, cuanto por la demencia y los deseos que la hermosa mujer despertaba en las profundidades del sacerdote. Las sesiones bíblicas de los miércoles eran para él un infierno, y no únicamente por verse en la necesidad de repeler las embestidas tántricas y new-ageras de la joven-icómo un engendro así podía estar en el grupo de estudio bíblico!-, sino porque en una sola noche concentraba todas las erecciones de la semana. Tenía que ser obra del mismísimo Ángel Negro que los otros cuatro convidados hubiesen cancelado justo en el último momento.

- ¡Hacer el bien y evitar el mal, principio fundamental de la ley natural!

-¿La ley natural?

-Axioma primero del orden moral. Evidente.

-Tendrás que explicarme con más detalle.

-El orden del universo nos revela que Dios existe, y que nada tiene que ver con esos impostores que frecuentas. Falsos profetas como ellos harían pensar, Dios me perdone, que el sacrificio de Cristo fue inútil. Míralo al pobre clavado en la cruz, falleciendo, expirando el último

* Escritor. 
VENUSTIANO REYES

hálito de vida, sudando las iniquidades de la humanidad. ¡Qué sacrificio! ¡Y ahora estos dementes juegan al dios!

¿No había que hacer el bien y evitar el mal? ¿Qué podía tener de malo deleitarse en la alcoba, los dos desnudos, los dos explorándose, los dos lamiéndose los sexos con frenesí y devoción? Sofía pensaba que el intercambio de flujos era la mejor manera de liberar las malas energías que se acumulan en el cuerpo y en el alma. Quien lo hace se quita un peso de encima. Quien no lo hace se reprime. Por éstas y otras razones, se decía, es necesario recorrer libremente el camino de la sexualidad. En caso de crisis, sexo. En caso de nerviosismo, sexo. A falta de sexo, sexo. Exceso de sexo, sexo-o, si se prefiere, ex-sexo-. Si de agotamiento se trata, sexo. Nada mejor para la inactividad que el sexo. El sexo cura los remordimientos, intensifica las alegrías, aplaca los dolores, libera las tensiones, matiza las pasiones, corrige los errores, estropea maravillosamente los aciertos. Sexo, sexo, sexo y más sexo. Quien siente dolor en el corazón, sólo tiene que abandonarse a él. Quien no tenga dolor en el corazón y desee tenerlo, pues también. Diría Sofía que este invento de Dios, acaso el mejor, es una especie de panacea. En cambio la represión siempre es tiranía, abuso de uno mismo y de los demás.

-Tanto abusa del sexo la ninfomaníaca...

112 -Como la virgen perpetua...

-¡Horror, horror!

-La primera por exceso, la segunda por defecto...

Ya lo decía Tomás de Aquino, ese gran artífice del edificio filosófico católico, basándose en Aristóteles: hay que buscar el justo medio. No se trata de sufrir ni de cometer injusticias, sino de ser justo. Tanto es despreciable el temerario como el cobarde. Es menester moderar los apetitos. ¿Y qué decir de la prudencia? Hacer lo que se debe en el momento que se debe, en el justo tiempo, no antes ni después, sin perder de vista, claro está, la vida como un todo: recta razón sobre el obrar total de un hombre que se dirige al fin último. Pero podría objetarse lo siguiente: si el universo está ordenado, y podemos descubrir dicho orden hasta en las más insignificantes criaturas, ¿no será contra natura reprimir hasta la flagelación nuestra dimensión erótica, que, a fin de cuentas, es parte de ese orden? 
-¡Animal racional!

-iAnimal erótico!

-¡Racional!

-¡Erótico!

-¿Zoón erotikón? ¡No me hagas reír!

-Animal risible...

-¡Vaya! Tienes respuestas para todo...

-Racional, risible, pero principalmente erótico.

En efecto, Sofía tenía respuestas para todo. No es fácil hablar y convencer a una mujer que efectúa sus operaciones intelectuales al modo angélico, por tántrica que pudiera ser, menos aún si posee un semblante de turca misteriosa que por sí mismo sería suficiente para turbar a cualquiera. Sus ojos son capaces de penetrar las entrañas de quien la observe, hasta el punto de hacerlo sentir desnudo. Pedro experimentó esa extraña sensación. Bastó una mirada para que su alma quedara en evidencia. Odió dar razón al ya de por sí odiado Jean Paul, y se dio cuenta que, en efecto, una simple mirada puede ser el infierno. Sólo el hombre tiene intimidad, por eso es pudoroso, y cuando dicha intimidad es descubierta por otro, cuando se está verdaderamente desnudo ante la alteridad, entonces el hombre se ruboriza y siente la vergüenza de la existencia.

-Animal pudoroso...

-Animal obsceno...

-Animal religioso...

-Animal profano...

-Animal sagrado...

-Animal abominable...

-Hecho a imagen y semejanza de Dios...

-Creador de un Dios hecho a su imagen y semejanza...

Pedro sabía que el parentesco con la divinidad, esa imagen y semejanza, no podía ser antropomórfica (es decir, morfológica), sino espiritual. Si en algo se parece el hombre a Dios es en el espíritu. De alguna manera las operaciones del espíritu humano son análogas a las operaciones de Dios. Claro que el hombre es un compuesto, ya sea de esencia y acto de ser, o de materia y forma, o bien un compuesto de sustancia y accidentes, de potencia y acto, o cualquiera de esas dicotomías tomistas 
VENUSTIANO REYES

que llevan a uno a afirmar que el ser necesario, Ipsum Esse Subsistens, es, valga la tautología, necesario. No cabe duda: Dios existe y punto. Él es el Ser-en-sí y ha donado, cortesía de su infinito amor, el ser-porparticipación a las criaturas.

-En las criaturas encontramos la huella del Creador.

-¿En todas las criaturas?

-En todas las criaturas.

No podía ser de otra manera. De hecho, la visión de Sofía era suficiente para atribuirla a sus padres como causa eficiente, pero a Dios como causa final, y sobre todo ejemplar. En lo que tocaba a la causa formal, no resultaba descabellado decir que ella era una verdadera diosa. Otra maldita erección. (¿Cuál será la causa material? ¿El falo? Joder, joder y más joder. La eficiente es, sin duda, la voluptuosidad ajena). ¡Pobre Pedro! El jugo de la espina se le ha puesto en movimiento. El semen es el principio activo que proporciona la forma, si hemos de creer las palabras del obeso Tomás. La madre proporciona sólo la materia. Mater, materia. ¡Qué cosas! La mujer es un hombre imperfecto. ¿Qué demonios le habrá faltado para ser perfecto? ¿Cojones? La filosofía de Tomás no es más que un instrumento de poder, y para tal instrumento, las mujeres son pecaminosas por naturaleza. Lujuriosas, se dijo Pedro.

-Veo que estás un poco turbado...

-No se de dónde sacas esas tonterías. ¿Turbado yo?

Pedro cruzó las piernas para disimular un poco la erección y relajar los músculos severamente excitados a causa de dos gotas de vino que viajaron voluptuosamente a través de los labios entreabiertos de Sofía. Si tan solo pudiera besarlos, o por lo menos tocarlos con la punta de los dedos... y sentir aquellos dientes nacarados... ¿Podría entonces decir "no" a Dios? La sonrisa de Sofía era divina. Sus dientes, su boca, su cuerpo completo eran ideales para el amor, para el sexo oral, para el sesenta y nueve y el noventa y seis, y el uno, el dos y el tres. La posición del misionero (esa araña de ocho patas que se desliza peligrosa y jadeante por la telaraña de las sábanas, y que se pica a sí misma, se autosodomiza y se penetra, un solo ser masturbándose bajo la luna) tenía que ser la favorita de Pedro. ¡Divina misión del Señor! El Cantar 
de los Cantares o el Kamasutra... ¡Ese es el dilema! Ser o no ser... la perfección última de los entes, el esse, el acto de ser, o se tiene o no se tiene, y si se tiene, entonces no es dilema. En todo caso, el problema radica en la siguiente cuestión: ¿de dónde demonios obtuvimos el ser? ¿La contingencia es la madre de la necesidad? ¿O a la inversa? El ser cuya esencia y esse se identifican no tiene mayor problema con la existencia. Pero para el hombre las cosas pueden ser mucho más complejas y desconcertantes. Dios debe estar muerto de risa a causa de los ridículos esfuerzos del hombre para conocerlo. Dios debe morirse de risa ante las miles y dispares interpretaciones, ante la sangre que brota en los enconos de los libros sagrados, ante los múltiples ritos que se practican a ratos y que dejan a los creyentes un tanto rotos al no saber cuáles son exactamente las rutas que los libren de convertirse en ratas. Muerto de risa. Un Dios muerto de risa.... ¡Se ha dicho muerto! ¡Vaya chiste divino! ¿Cómo podría estar Dios muerto? ¡Ni siquiera Nietzsche con toda una legión de filósofos alemanes podría hacerle cosquillas! Lo que es, es. Lo que no es, no es. ¿Acaso no es claro el principio de no-contradicción? ¿Cuál es entonces el dilema?

-Animal problemático...

-Animal investigador...

-Animal idólatra...

-Animal que reconoce su dependencia hacia el Ipsum Esse Subsistens... -Animal traidor, depredador...

-El más perfecto entre los vivientes materiales...

-El más imperfecto de los seres espirituales...

Tenía razón Sofía respecto a la imperfección. La belleza de su cuerpo -y para el caso la belleza de los cuerpos de todas las mujeres y hombres bellos- era inversamente proporcional a la inmundicia de las funciones corporales. Justo ahí, en ese majestuoso y soberbio trasero se encontraba el escape de la pestilencia, el desagüe de lo superfluo. Detrás de aquella boca sagrada se hallaba el tubo que deglute los nutrientes y los conduce a la bolsa ácida. Los besos son la sublimación de las funciones digestivas, digestión al revés, cuerpo en forma de gas o de eructo que se niega a recorrer el tortuoso camino que comienza en la boca y 
escapa por el ano. La penetración anal es un supositorio de descomunal tamaño, un sello que crea el indescriptible vacío en el recto y en los intestinos, un tapón que deja en silencio a la serpiente que se aloja en el vientre. La serpiente de la boca inocula con furiosos besos el veneno a la serpiente de los intestinos. El amor de concupiscencia no deja de tener un aspecto casi necrófilo, sádico y masoquista. ¡Qué bellos son los cuerpos! ¡Qué horror sus funciones, sus excreciones, sus exorcismos materiales! ¡Cómo no iba a compadecerse el Creador ante tanta imperfección al grado de hacerse hombre para salvar al hombre! ¡Dejó irredentos a los ángeles rebeldes, en cuya naturaleza no tuvo intención el Padre de engendrarse! Los problemas de los ángeles son insignificantes si se los compara con los de la bestia racional. Debe haber algo muy especial en el hombre. ¿Tal vez la extraña combinación de sensibilidad y espiritualidad que lo convierte en un ser erótico? Los ángeles no podrían experimentar las delicias del sexo, pues para empezar carecen de él. ¡Lástima que lastima! Los ángeles no pueden ser eróticos. ¡Cómo imaginar el intercambio de fluidos y gases amorosos en las formas puras!

-El hombre es la criatura más cara a Dios.

-¿Más que los ángeles?

Pedro no respondió de inmediato. Antes de que sus labios pronunciaran “Sí, más que los ángeles”, pensó en Sofía. Ella, primero que nadie, hombres o ángeles, debía ser más cara a Dios.

-Sí, más que los ángeles.

-¿Cómo puedes saberlo?

-Dios se hizo hombre en Cristo, no ángel.

Si Cristo en vez de hombre se hubiese hecho ángel, ¿cómo diablos hubiera sido crucificado? El hombre es brutal, y por ello requirió mayor compasión. Esa pobre bestia ligeramente peluda, punto intermedio entre los ángeles menos perfectos y los primates, había sido una verdadera equivocación divina. Hasta Dios tiene que enmendar sus errores.

-En el hombre -dijo Pedro con cierta solemnidad-se reúnen las dimensiones espirituales y materiales. De ahí su riqueza y su indigencia...

Era la indigencia de Sofía lo que inquietaba a Pedro. Satanás tenía que ser bellísimo. El pobre hombre se sintió tentado. Sofía estaba muy 
cerca de él, casi olía el aroma de su piel, casi podía rozar sus manos y percibir su aliento en la cara. Se acercó tímido y temeroso. Le pareció que la mujer cedía y que lo llamaba con los ojos, con la mirada turca y los dientes nacarados, con la nariz ligeramente respingada y con los labios carnosos. Lo llamaba con ese par de senos atrapados detrás de la suave seda, le gritaba con los pezones erectos, con las axilas pobladas de vello, con el pubis, con el ombligo, con cada uno de sus lacios cabellos, negros y largos como la noche, negros y largos como el pecado, negros y largos como el placer. Pedro se estremeció y apretó las piernas en un intento infructuoso para doblegar su falo y contener la actividad de los testículos. Pero en realidad decir no a Sofía era como decir no a Dios. Moriré castrado, pensó aquel hombre convertido en parodia de sí mismo. Su sexo fue látigo que se deslizó como gusano entre sus calzones. Era una lombriz ciega que avanzaba lenta y constante a través del lodo de la vida. Era una oruga que se entumía y se estiraba a lo largo de un tallo mojado con el rocío de la virginidad y de la santidad, humedecido por las frescas gotas de la ternura, de la juventud, de la ignorancia y de la inocencia, gotas que no tienen cabida en su perverso mundo... ese mundo ordenado por un Dios que sólo es compatible con una pequeña parte de la humanidad... una parte que clama el monopolio absoluto de la verdad y de la salvación. El gusano avanzó carcomiendo la carne, lastimando y sodomizando el alma, ganando terreno en el prepucio imaginario de un cadáver, para deslizarse suavemente sobre el periné, internarse en el ano y salir finalmente por la boca putrefacta y rígida desde donde otros gusanos inician la peregrinación de ese circuito infernal que es la muerte, de ese ciclo maldito que termina con la reducción al absurdo de aquello que algún día estuvo animado. El gusano de su verga, peludo y circunciso, estuvo a punto de vencer las inhibiciones y el prejuicio. Pero él lo dominó. Sólo bastó abandonarse en Dios: moriré castrado, pero me salvaré. Perdiéndose un poco en sus tribulaciones, Pedro se distrajo y no se dio cuenta que Sofía se había acercado tanto que tenía la mano sobre una de sus piernas, que las demás extremidades estaban casi entrelazadas (los misioneros convertidos en arañas), que los labios estaban por unirse, y que las sierpes húmedas comenzaban la danza del amor, 
a punto de enroscarse y de lamerse. Al recobrar conciencia, el hombre apartó a la mujer. Ella cogió la copa y ensayó una sonrisa relajada, luciferina. Pedro se levantó con unos terribles deseos de orinar. La micción desaguando la existencia. En el cuarto de baño observó su miembro colgante. Lucía casto y triste. Sacó la navaja suiza (¡el Papa y su guardia, válgame Dios!) y paseó la hoja metálica lentamente sobre el glande y la base. Los vellos quedaban atrapados por un momento, y luego, al liberarse, se erizaban como árboles que se mecen y bailan al son del huracán. El paso amenazante de la navaja produjo el efecto contrario: en vez de perder la erección, la verga adquirió una firmeza de piedra. El órgano estaba hecho para el placer. Pedro sintió una terrible rabia y se maldijo. Asustado por sus pensamientos, se dispuso a cercenar el miembro, pero el ángel con el que había estado cenando lo salvó:

- ¿Te encuentras bien? -preguntó Sofía desde el otro lado de la puerta.

¡Qué clase de pregunta era ésa!, pensó el hombre.

-Sí... me encuentro bien.

¡Qué clase de violación al principio de no-contradicción implicaba esa respuesta!

-Todos en la vida llegamos al necrófilo punto en que desearíamos herirnos el sexo - dijo Sofía.

¡Qué clase de afirmación era ésa? ¿Acaso era vidente o adivinadora? Pedro no contestó. Jaló la cadena del váter, lo que de algún modo le quitó un peso de encima. Creyó que parte de sus iniquidades se habían ido al caño. Después de unos segundos salió con un halo de triunfo, con la satisfacción de quien ha vencido una resistencia, con la convicción más firme en sus ideas y, créase o no, con el falo en reposo. Entonces se dispuso a alabar a Dios y demostrarle a Sofía el orden del universo. Ésa sería su última cena. Lo que no me mata me fortalece, dijo con una sonrisa en el rostro esbozada. 